\title{
Kinetic study of methane hydrate formation in the presence of carbon nanostructures
}

\author{
Saeid Abedi-Farizhendi ${ }^{1,2} \cdot$ Mina Iranshahi ${ }^{2} \cdot$ Abolfazl Mohammadi $^{3} \cdot$ Mehrdad Manteghian $^{1} \cdot$ \\ Amir H. Mohammadi ${ }^{4,5}$
}

Received: 2 June 2018 / Published online: 3 June 2019

(c) The Author(s) 2019

\begin{abstract}
The effect of synthesized nanostructures, including graphene oxide, chemically reduced graphene oxide with sodium dodecyl sulfate (SDS), chemically reduced graphene oxide with polyvinylpyrrolidone, and multi-walled carbon nanotubes, on the kinetics of methane hydrate formation was investigated in this work. The experiments were carried out at a pressure of 4.5 $\mathrm{MPa}$ and a temperature of $0{ }^{\circ} \mathrm{C}$ in a batch reactor. By adding nanostructures, the induction time decreases, and the shortest induction time appeares at certain concentrations of reduced graphene oxide with SDS and graphene oxide, that is, at a concentration of $360 \mathrm{ppm}$ for reduced graphene oxide with SDS and $180 \mathrm{ppm}$ for graphene oxide, with a $98 \%$ decrease in induction time compared to that in pure water. Moreover, utilization of carbon nanostructures increases the amount and the rate of methane consumed during the hydrate formation process. Utilization of multi-walled carbon nanotubes with a concentration of $90 \mathrm{ppm}$ showes the highest amount of methane consumption. The amount of methane consumption increases by $173 \%$ in comparison with that in pure water. The addition of carbon nanostructures does not change the storage capacity of methane hydrate in the hydrate formation process, while the percentage of water conversion to hydrate in the presence of carbon nanotubes increases considerably, the greatest value of which occurres at a $90 \mathrm{ppm}$ concentration of carbon nanotubes, that is, a $253 \%$ increase in the presence of carbon nanotubes compared to that of pure water.
\end{abstract}

Keywords Clathrate hydrate $\cdot$ Kinetics $\cdot$ Carbon nanostructures $\cdot$ Graphene oxide $\cdot$ SDS $\cdot$ PVP

\section{Introduction}

Edited by Xiu-Qin Zhu

Mehrdad Manteghian

manteghi@modares.ac.ir

$\triangle$ Amir H. Mohammadi

amir_h_mohammadi@yahoo.com

1 Faculty of Chemical Engineering, Tarbiat Modares University, Tehran, Iran

2 Department of Petroleum Engineering, South Tehran Branch, Islamic Azad University, Tehran, Iran

3 Department of Chemical Engineering, University of Bojnord, Bojnord, Iran

4 Institut de Recherche en Génie Chimique et Pétrolier (IRGCP), Paris Cedex, France

5 Discipline of Chemical Engineering, School of Engineering, University of KwaZulu-Natal, Howard College Campus, King George V Avenue, Durban 4041, South Africa
Gas hydrates, which are also recognized as clathrate hydrates, are non-stoichiometric crystalline compounds that are formed by combination of gas (or some small volatile liquid) molecules with water through hydrogen bonding. Gas hydrate structures have three common types which are named structure I (sI), structure II (sII), and structure $\mathrm{H}(\mathrm{sH})$ (Sloan and Koh 2008). Because of the high storage capacity of gas hydrates, these compounds have a potential for many industrial applications such as natural gas storage and transportation, gas separation and sequestration, hydrogen storage, refrigeration systems, and water desalination (Adisasmito et al. 1991; Chatti et al. 2005; Eslamimanesh et al. 2012; Ji et al. 2001; Mohammadi et al. 2017b, 2018; Ohgaki et al. 1996).

One of the challenges in the industrial applications of gas hydrates is their low formation rate (Sloan and Koh 2008). Nanoparticles usage in the formation of hydrate has been proposed in natural gas storage and transfer by 
hydrate technology. Various studies have been undertaken for increasing the gas storage capacity and the hydrate formation rate, as well as reducing the induction time using nanoparticles in comparison with pure water (Aliabadi et al. 2015; Arjang et al. 2013; Chari et al. 2013; Ganji et al. 2013; Govindaraj et al. 2015; Mohammadi 2017; Mohammadi et al. 2011, 2014; Najibi et al. 2015; Pahlavanzadeh et al. 2016; Rahmati-Abkenar et al. 2017).

In 2014, Mohammadi et al. (2014) investigated the effects of sodium dodecyl sulfate (SDS) and silver nanoparticles on the kinetic parameters (storage capacity of carbon dioxide, water to hydrate conversion, the amount of gas uptake, induction time, and hydrate formation rate) in the process of carbon dioxide hydrate formation. They found that SDS and silver nanoparticles do not have a significant effect on the kinetic parameters of carbon dioxide hydrate formation. However, the mixture of SDS + silver nanoparticles can increase the storage capacity of carbon dioxide in the process of carbon dioxide hydrate formation. Rahmati-Abkenar and coworkers (Rahmati-Abkenar et al. 2017) have studied the effect of silver nanoparticles on the kinetics of methane hydrate formation and found that utilization of triangular silver nanoparticles can reduce the induction time of methane hydrate formation up to $97 \%$ in comparison with pure water. The impact of $\mathrm{Al}_{2} \mathrm{O}_{3}, \mathrm{SiO}_{2}$, silver and copper nanoparticles on the kinetics of hydrate formation was investigated by Said et al. (Said et al. 2016). Their studies show that nanoparticles with high specific surface area have the most positive effect on the kinetics of gas hydrate formation (Said et al. 2016).

The use of carbon nanostructures in gas hydrate formation was first reported by Park et al. (2010). On adding multi-walled carbon nanotubes (MWCNTs) and comparing it with pure water, they found a 300 percent increase in the consumed gas amount and a decrease in the induction time (Park et al. 2010).

In another study, Park et al. (Park et al. 2012) investigated carbon nanotubes and their oxide. Their results show that carbon nanotubes can increase the hydrate formation rate, and the consumed gas amount in the presence of oxidized multi-walled carbon nanotubes (OMWCNTs) was reported to be 4.5 times that of pure water. Zhou et al. (Zhou et al. 2014) studied the effect of graphite nanoparticles on carbon dioxide hydrate formation. Their investigation indicates that adding graphite nanoparticles can increase the amount of gas consumed by $12.8 \%$ and reduce the induction time by $80.8 \%$, in comparison with pure water. The impact of MWCNTs on dissolution and hydrate growth rates of carbon dioxide has been studied by Pasieka and coworkers (Pasieka et al. 2015). They concluded that MWCNTs have a negligible effect on the kinetics of methane dissolution and hydrate growth rate (Pasieka et al. 2015).

Rezaei et al. (2016) studied the effect of graphene oxide and SDS on the kinetics of ethylene hydrate formation. They found that utilization of graphene oxide with a concentration of $150 \mathrm{ppm}$ shows the lowest induction time, which decreased by $96 \%$ in comparison with pure water. They also concluded that low concentrations of graphene oxide do not show a significant effect on the rate of hydrate formation, while the gas consumption and the storage capacity increase with higher concentrations of graphene oxide. Mohammadi and coworkers studied the effect of $\beta$-cyclodextrin, MWCNTs, and SDS on the amount and the rate of methane dissolution in water (Mohammadi et al. 2017a). They found that these additives increase the rate and the amount of methane dissolution, compared to pure water. Abedi-Farizhendi and coworkers (Abedi-Farizhendi et al. 2018) studied propane hydrate formation in the presence of carbon nanostructures and SDS. They concluded that these additives promote the hydrate nucleation and growth rate.

In the present work, the kinetics of methane hydrate formation in the presence of graphene oxide (denoted as GO), chemically reduced graphene oxide with SDS (denoted as $\mathrm{CR}(\mathrm{GO}+\mathrm{SDS})$ ), chemically reduced graphene oxide with PVP (denoted as CR(GO + PVP)), and multi-walled carbon nanotube (denoted as MWCNT) at the concentrations of 90 , 180, 360, and 540 ppm have been studied. Moreover, parameters of gas consumption, induction time, storage capacity, hydrate constant, and hydrate formation rate were studied.

\section{Experimental}

\subsection{Materials}

In order to conduct this study, materials such as potassium permanganate $\left(\mathrm{KMnO}_{4}, 99 \%\right.$ purity), sodium nitrate $\left(\mathrm{NaNO}_{3}, 99 \%\right)$, sulfuric acid $\left(\mathrm{H}_{2} \mathrm{SO}_{4}, 97 \%\right)$, hydrogen peroxide $\left(\mathrm{H}_{2} \mathrm{O}_{2}, 30 \%\right)$, hydrochloric acid $(\mathrm{HCl}, 37 \%)$, sodium dodecyl sulfate (SDS, $\mathrm{NaC}_{12} \mathrm{H}_{25} \mathrm{SO}_{4}, 98 \%$ ), polyvinylpyrrolidone (PVP, $\left.\left(\mathrm{C}_{6} \mathrm{H}_{9} \mathrm{NO}\right)_{n}, 99 \%\right)$, ascorbic acid $\left(\mathrm{C}_{6} \mathrm{H}_{8} \mathrm{O}_{6}\right.$, 99\%), and ammonia solution $\left(\mathrm{NH}_{4} \mathrm{OH}, 25 \%\right)$ were acquired from Merck, and graphite (flakes) with 99\% purity and multi-walled carbon nanotube (MWCNT, 98\%) were purchased from NGS graphite GmbH and NAFZA, respectively. Methane was provided by Technical Gas Service with a purity of $99.9 \%$. In all tests, de-ionized water was used. Aqueous solutions were prepared by using an analytical balance with an accuracy of $0.1 \mathrm{mg}$.

\subsection{Preparation and characterization of carbon structures}

Graphene oxide needed for the experiments was synthesized using the method of modified Hummers (Dreyer et al. 2010). Graphite and sodium nitrate with masses of $5 \mathrm{~g}$ and $2.5 \mathrm{~g}$, respectively, were added to a $98 \%$ pure sulfuric acid with 


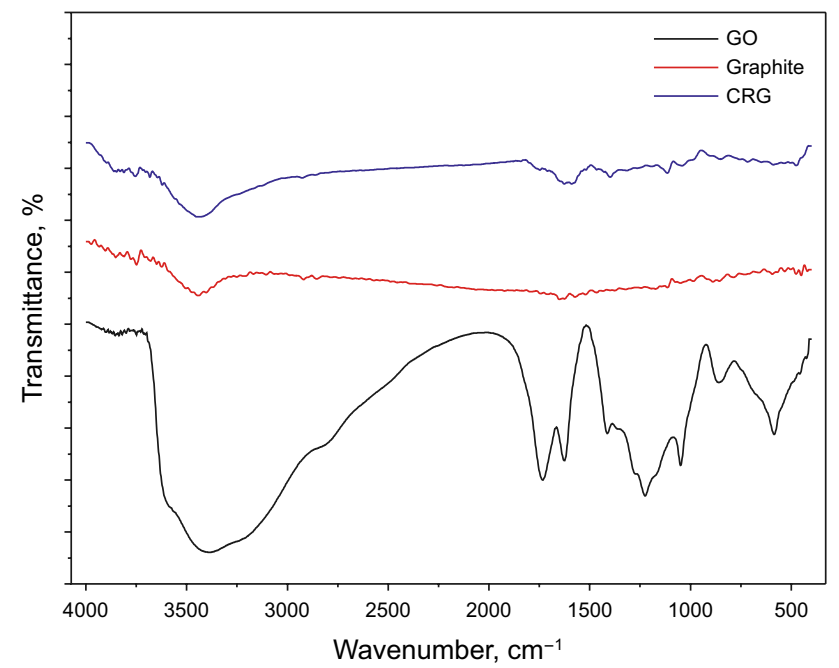

Fig. 1 Infrared spectrum of graphene oxide, graphite, and chemical reduction of graphene oxide samples

a volume of $150 \mathrm{~mL}$, as for the oxidizing agent, $15 \mathrm{~g}$ of potassium permanganate was added to the graphite solution. After $24 \mathrm{~h}$ of the reaction at the temperature of $35^{\circ} \mathrm{C}$, the solution was diluted using de-ionized water with a volume of $300 \mathrm{~mL}$. Then, $100 \mathrm{~mL}$ hydrogen peroxide aqueous solution with a concentration of $3 \%$ was added to the solution and stirred for $2 \mathrm{~h}$. The entire mixture was then filtered and washed repeatedly, using water and hydrochloric acid. After washing, graphene oxide was obtained by drying the mixture and dispersing the powder in water using a rather mild sonication. Chemically reduced graphene oxide was obtained by the addition of ascorbic acid ( $41 \mathrm{mM})$ to graphene oxide in the presence of SDS, and PVP acting as a stabilizer $(\mathrm{pH}=9$, controlled by ammonia).

\subsection{Fourier transform infrared spectroscopy (FT-IR)}

Figure 1 shows the infrared spectrum of graphene oxide, graphite, and chemically reduced graphene oxide samples. As can be seen, in the infrared spectrum of graphene oxide sample, the observed peaks at $3400,1730,1623$, and $1225 \mathrm{~cm}^{-1}$, respectively, represent the stretching vibration of hydroxyl groups, the stretching vibration of the $\mathrm{C}=\mathrm{O}$ bonds in the carboxyl groups, skeletal stretching vibration of non-oxidized $\mathrm{C}=\mathrm{C}$ groups in graphene plates, and vibration of epoxy groups. Also, the peaks at $1410 \mathrm{~cm}^{-1}$ and $1050 \mathrm{~cm}^{-1}$ are attributed to the bending vibration of hydroxyl groups. It is important to mention that the observed peak at $860 \mathrm{~cm}^{-1}$ represents epoxy groups. However, in the chemically recovered sample, the intensity of these peaks has either been substantially diminished or the peaks completely vanished. Only at $3430 \mathrm{~cm}^{-1}$ was a significant peak in the CRG sample witnessed that can be

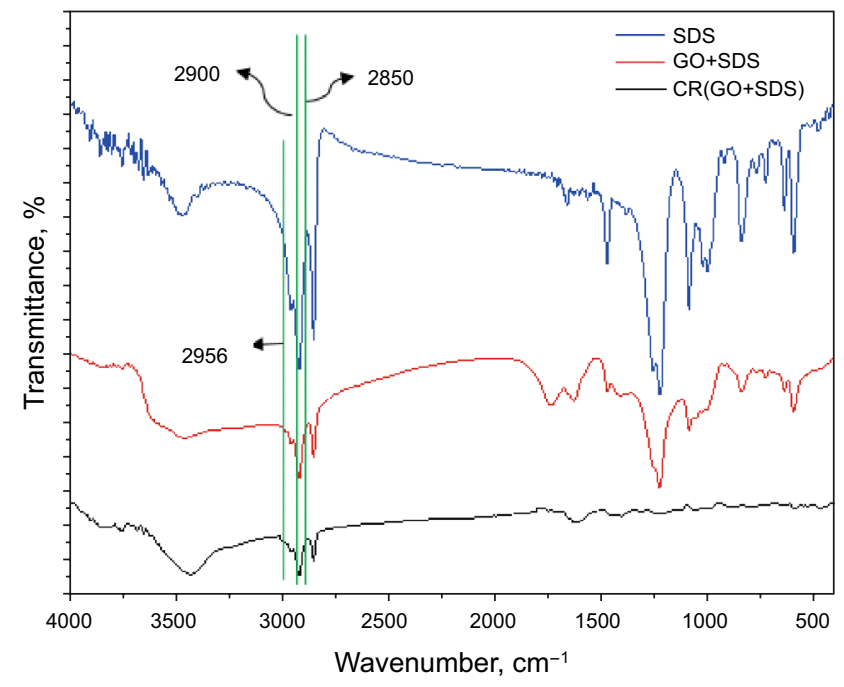

Fig. 2 SDS, GO +SDS, and $\mathrm{CR}(\mathrm{GO}+\mathrm{SDS})$ infrared spectra

due to both the moisture absorption of the samples and the preservation of some of the carboxyl groups, as this peak was observed likewise in the graphite sample (Chua and Pumera 2013; Fernández-Merino et al. 2010; Waltman et al. 1993). One should note that chemical reduction does not have the ability to eliminate all the chemical groups present on the graphene sheet, and some carboxyl groups will remain on the plates (Tran et al. 2014).

To investigate the absorption of surfactants on the surface of graphene plates, IR-spectroscopy was conducted on SDS, GO + SDS, and CR(GO + SDS) samples.

First, the samples were thoroughly washed with deionized water and filtered to remove excess amounts of surfactant that had not been absorbed on graphene plates. The results of this test are shown in Fig. 2.

With regard to the peaks observed at 2850 and $2900 \mathrm{~cm}^{-1}$ that are due to the symmetric and asymmetric stretching of $\mathrm{CH}_{2}$ groups and the one picked up at $2956 \mathrm{~cm}^{-1}$, which is attributed to $\mathrm{CH}_{3}$ groups that were constant for all samples, it can be concluded that sodium dodecyl sulfate surfactant was absorbed onto the graphene plates, which was not separated from the latter even after being completely washed and recovered (Zhao and Gao 2004).

Also, PVP, GO + PVP, and CR(GO+PVP) samples were tested by infrared spectroscopy for the same purpose, and the results of this test are shown in Fig. 3. The peaks observed at $2920 \mathrm{~cm}^{-1}$ and $2854 \mathrm{~cm}^{-1}$ infrared spectra are related to the symmetric and asymmetric stretching of $-\mathrm{CH}_{2}$ groups, those captured at $1620 \mathrm{~cm}^{-1}$ and $1425 \mathrm{~cm}^{-1}$ spectra show the $\mathrm{C}-\mathrm{N}$ groups, and the ones at $1320 \mathrm{~cm}^{-1}$ spectra represent $\mathrm{C}-\mathrm{H}$. Given the observed peaks, it can be concluded that this surfactant was adsorbed onto graphene plates (Basha 2010). 


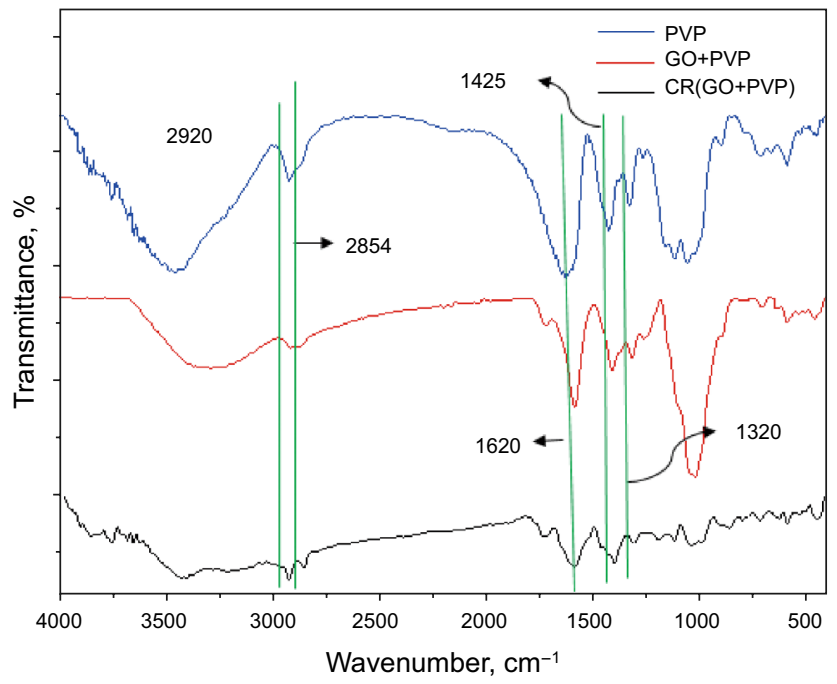

Fig. 3 Infrared spectra of PVP, GO + PVP, and CR(GO+PVP)

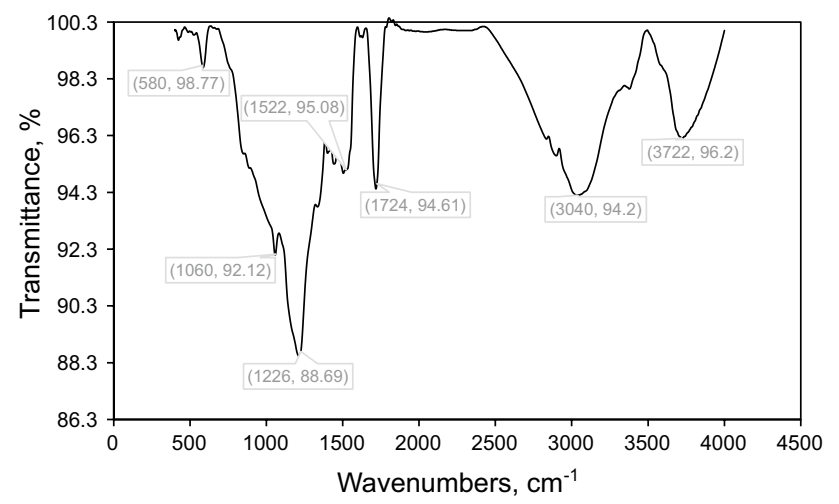

Fig. 4 Infrared spectra of multi-walled carbon nanotube (MWCNT)

Figure 4 shows the infrared spectrum of multi-walled carbon nanotube (MWCNT) samples which were purchased from NAFZA.

The SEM images captured from synthesized GO, chemically reduced graphene oxide $\mathrm{CR}(\mathrm{GO}+\mathrm{SDS})$, and chemically reduced graphene oxide $\mathrm{CR}(\mathrm{GO}+\mathrm{PVP})$ are shown in Fig. 5. Figure 6 illustrates an image of the carbon nanotubes, which was used in the present experiment. This image was taken by TEM.

\subsection{Apparatus}

A schematic diagram of the experimental setup used in this research is shown in Fig. 7. To conduct the experiments, a stainless steel jacketed reactor with an inner volume of $460 \mathrm{~cm}^{3}$ was used. The chamber inside this reactor was equipped with two needle valves, capable of withstanding 6000 psi pressure, to inject and discharge water and gas. Two vents were also fitted on the outer wall of the reactor for the coolant material to enter and exit, which in these experiments were a mixture of ethylene glycol and water. The gas and aqueous solution were mixed by an electric motor, and the oscillatory movement of the reactor causes the phases to be in contact with each other during the tests.

A 26.600 pressure transducer made by BD SENSORS was used to measure the pressure inside the reactor. This transducer can measure pressures up to $10 \mathrm{MPa}$ with a precision of $\pm 0.1 \mathrm{MPa}$. The temperature inside the reactor was measured using a thermometer with a precision of $\pm 0.1^{\circ} \mathrm{C}$. The captured data were transmitted to a computer for processing at the interval of $20 \mathrm{~s}$. Since the experiments had to be executed at low and constant temperatures, an RE-106 temperature bath made by Louda Inc. with a precision of $\pm 0.1{ }^{\circ} \mathrm{C}$ was utilized for controlling the temperature inside the reactor.

\subsection{Experiment method}

As a first step, the reactor was washed for 30 min with tap water and then washed with de-ionized water seven times, at the beginning of each test. A vacuum pump, capable of creating vacuum conditions to $0.07 \mathrm{MPa}$, was used to evacuate the air inside the reactor. Later, the de-ionized water or the carbon nanotube structures were injected into the reactor.

Then, the temperature of the reactor was set to the desired temperature. In order to mix water/aqueous solution and gas properly for hydrate formation, the electric motor was set at $30 \mathrm{rpm}$. The gas was injected to the reactor with pressure up to $4.5 \mathrm{MPa}$; after that, the temperature inside the reactor reached $1{ }^{\circ} \mathrm{C}$.

Hydrate formation is accompanied by a pressure drop and a slight temperature rise inside the reactor, whereas the latter is owing to the exothermic nature of this reaction. The hydrate formation reaction was assumed to be completed when pressure change in time became very small, leveling out with a variation of $0.05 \mathrm{MPa}$ per hour. The time and pressure data were recorded during the tests, at the interval of $20 \mathrm{~s}$.

\section{Results and discussion}

\subsection{Induction time}

The prominent parameter in the nucleation process is the induction time. While not being a fundamental physical characteristic, it is derived empirically, giving pivotal information on the kinetics of nucleation or growth (Christiansen and Sloan 1995). The induction time is the time spent until the formation of hydrate phase (Sloan and Koh 2008). 
Fig. 5 SEM images of synthesized a graphene oxide (GO), b chemically reduced graphene oxide $\mathrm{CR}(\mathrm{GO}+\mathrm{PVP})$, and $\mathbf{c}$ chemically reduced graphene oxide $\mathrm{CR}(\mathrm{GO}+\mathrm{SDS})$
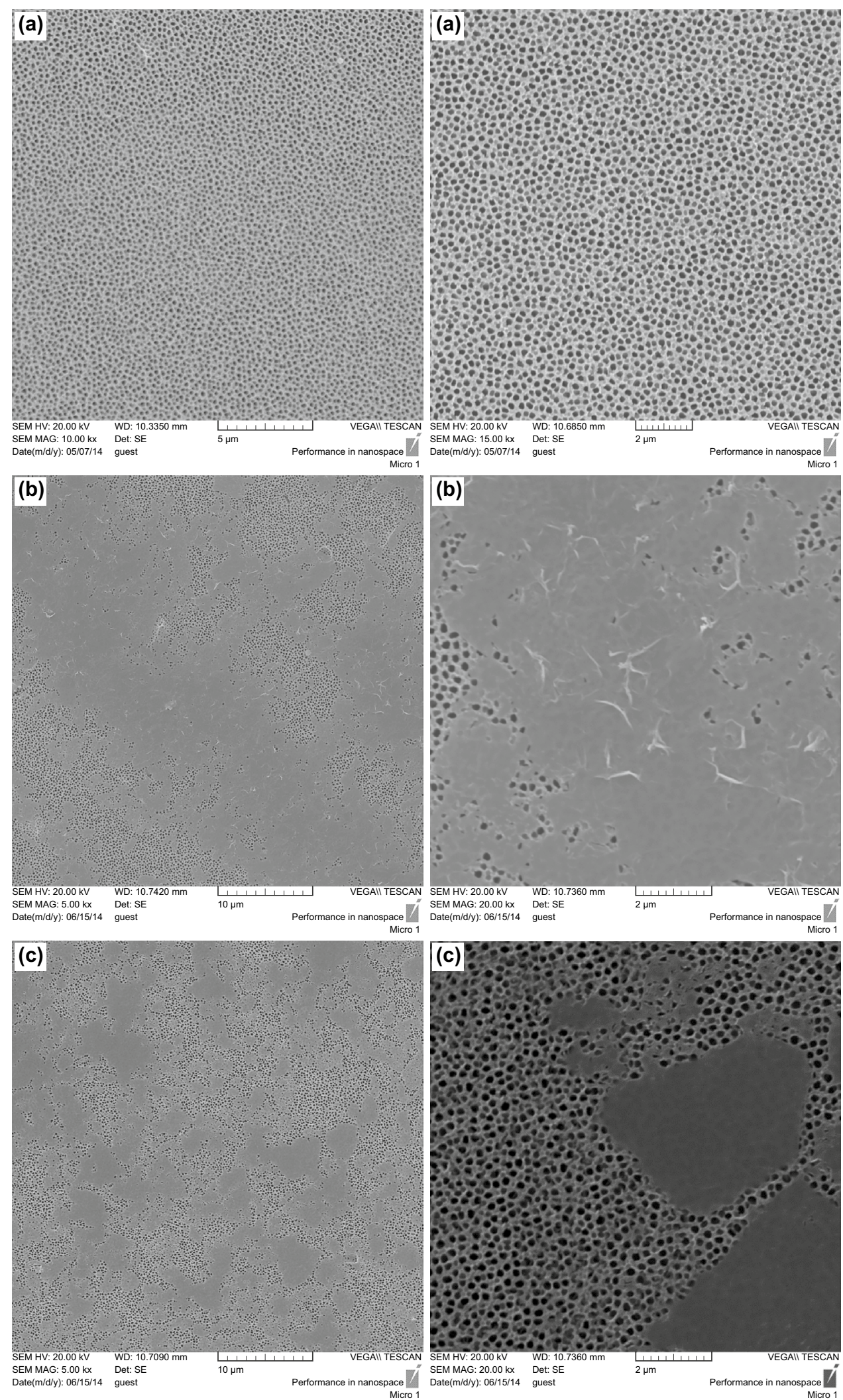

In order to measure the induction time in the presence of carbon nanostructures (graphene oxide GO, chemically reduced graphene oxide with SDS $(\mathrm{CR}(\mathrm{GO}+\mathrm{SDS}))$, chemically reduced graphene oxide with PVP (CR(GO + PVP)), and multi-walled carbon nanotube (MWCNT)), experiments were executed in accordance with 


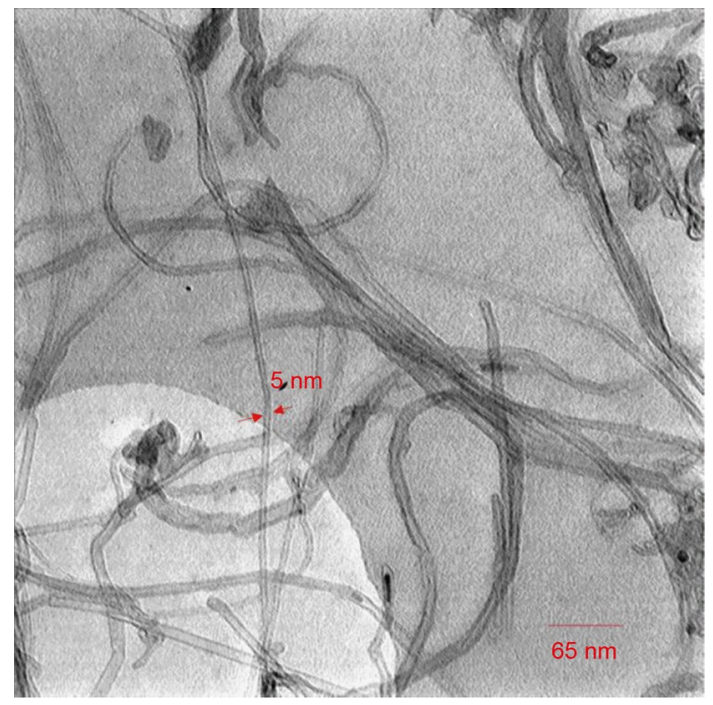

Fig. 6 TEM image of carbon nanotubes

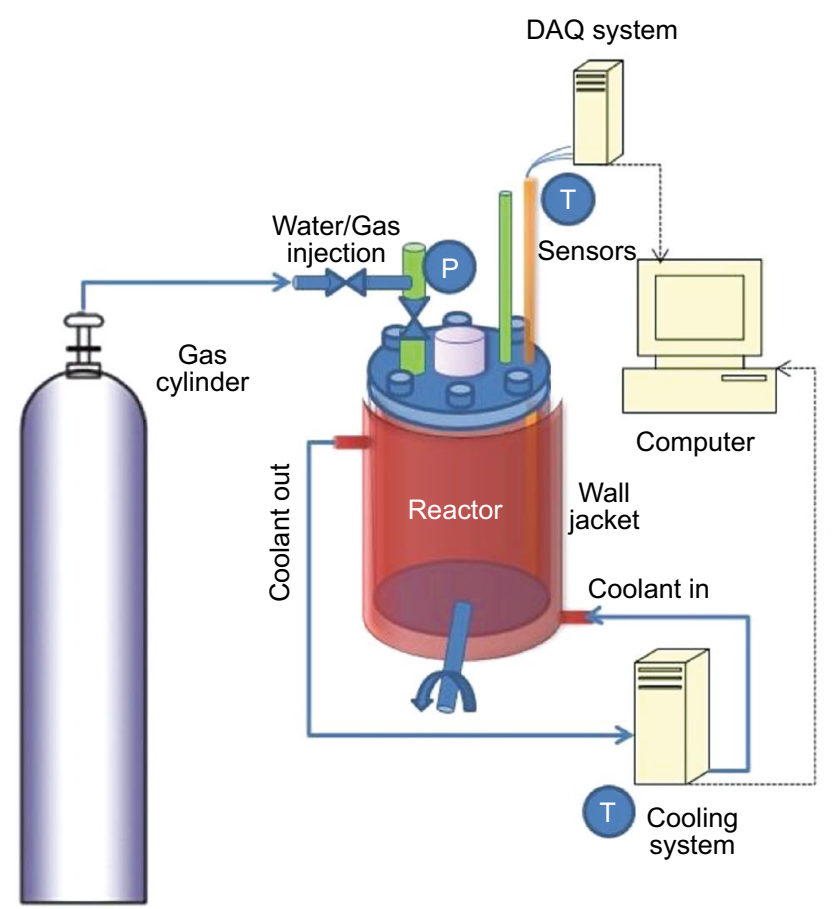

Fig. 7 The schematic diagram of the apparatus

the aforementioned procedure, each test was repeated five times, and an average value and the standard error for it are reported. Table 1 shows the induction time measured in the presence of graphene oxide GO, chemically reduced graphene oxide with SDS $(\mathrm{CR}(\mathrm{GO}+\mathrm{SDS}))$, chemically reduced graphene oxide with PVP $(\mathrm{CR}(\mathrm{GO}+\mathrm{PVP}))$, and multi-walled carbon nanotube (MWCNT) at the concentrations of 90, 180, 360 , and $540 \mathrm{ppm}$, respectively. It should be noted that the
Table 1 Induction time of methane hydrate in the presence of carbon nanostructures

\begin{tabular}{lllll}
\hline Set number & Concentration, ppm & $T,{ }^{\circ} \mathrm{C}$ & $P, \mathrm{MPa}$ & $\begin{array}{l}\text { Induction } \\
\text { time, min }\end{array}$ \\
\hline 1 & Pure water & 1 & 4.5 & $57 \pm 2$ \\
2 & CR(GO+SDS) (90) & 1 & 4.5 & $11 \pm 3$ \\
3 & CR(GO+SDS) (180) & 1 & 4.5 & $5 \pm 3$ \\
4 & CR(GO+SDS) (360) & 1 & 4.5 & $1 \pm 3$ \\
5 & CR(GO+SDS) (540) & 1 & 4.5 & $9 \pm 3$ \\
6 & GO (90) & 1 & 4.5 & $10 \pm 2$ \\
7 & GO (180) & 1 & 4.5 & $1 \pm 2$ \\
8 & GO (360) & 1 & 4.5 & $2 \pm 2$ \\
9 & GO (540) & 1 & 4.5 & $8 \pm 2$ \\
10 & MWCNT (90) & 1 & 4.5 & $7 \pm 2$ \\
11 & MWCNT (180) & 1 & 4.5 & $3 \pm 2$ \\
12 & MWCNT (360) & 1 & 4.5 & $4 \pm 2$ \\
13 & MWCNT (540) & 1 & 4.5 & $14 \pm 2$ \\
14 & CR(GO+PVP) (90) & 1 & 4.5 & $20 \pm 3$ \\
15 & CR(GO+PVP) (180) & 1 & 4.5 & $8 \pm 3$ \\
16 & CR(GO+PVP) (360) & 1 & 4.5 & $11 \pm 3$ \\
17 & CR(GO+PVP) (540) & 1 & 4.5 & $18 \pm 3$ \\
\hline
\end{tabular}

induction time was measured at a pressure of 4.5 MPa and a temperature of $1{ }^{\circ} \mathrm{C}$, as mentioned earlier. As can be seen, for all carbon nanostructures at all concentrations, there is a decrease in the induction time in comparison with pure water.

Utilization of graphene oxide and multi-walled carbon nanotubes in the process of gas hydrate formation provides external surfaces for heterogeneous nucleation of methane hydrate nuclei. Heterogeneous nucleation of gas hydrates is more kinetically favorable than homogeneous nucleation. In this type of nucleation, the effective surface energy is lower than in homogeneous nucleation, causing lower free energy and a lower nucleation barrier. Additionally, the carbon nanostructures used, by providing numerous nucleation sites, significantly increase the effective surface area. Therefore, the mass transfer of solution increases resulting in shorter induction time. On the other hand, movement of the nanostructures used by decreasing the resistance within the gas/liquid interface increases the mass transfer coefficient and consequently reduces the induction time of methane hydrate formation.

The induction time of methane hydrate formation in pure water is $57 \mathrm{~min}$, while the maximum value of induction time in the presence of tested additives is $20 \mathrm{~min}$. The minimum induction time of methane hydrate formation was obtained for the aqueous solutions of GO with the concentration of $180 \mathrm{ppm}$ and chemically reduced graphene oxide + SDS $(\mathrm{GO}+\mathrm{SDS})$ with a concentration of $360 \mathrm{ppm}$.

Rezaei et al. (2016) reported that at a concentration of $150 \mathrm{ppm}$ of graphene oxide, the lowest induction time was 
obtained in comparison with pure water. In this study, at all concentrations, the induction time was less than pure water. It is possible that the induction time of methane hydrate is reduced under the influence of carboxylic and hydroxyl groups in the structure of graphene oxide.

According to Park et al. (2010), the addition of multiwalled carbon nanotube (MWCNT) can decrease the time of hydrate formation, while in this research, the addition of carbon nanotubes at all concentrations resulted in a lower induction time than pure water.

Due to the very high thermal properties of chemically reduced graphene oxide (Balandin et al. 2008), it is likely to accelerate hydrate formation and reduce induction time. As observed in chemically reduced graphene oxide with SDS $(\mathrm{CR}(\mathrm{GO}+\mathrm{SDS}))$, for all of the concentrations, the induction time is less than pure water.

\subsection{Amount and rate of gas consumed in hydrate formation}

The consumed gas content and rate in the hydrate formation are important parameters in the process of gas hydrate formation. The amount of gas consumption in methane hydrate formation is given by the following equation (Smith et al. 2005):

$\Delta n_{\mathrm{CH}_{4}}=\frac{1}{R}\left(\frac{P_{0} V_{0}}{Z_{0} T_{0}}-\frac{P_{t} V_{t}}{Z_{t} T_{t}}\right)$

where $P$ and $T$ are the pressure and the temperature inside the reactor, respectively, $V$ is the gas volume within the cell, $R$ is the global constant for gases, and $Z$ is the gas compression coefficient, which is calculated using the Peng-Robinson equation (Peng and Robinson 1976). The indices 0 and $t$ represent, respectively, the conditions of the cell at $t=0$ and $t$. The gas volume inside the cell is time dependent. Mohammadi et al. suggested the following equation for calculation (Mohammadi et al. 2014):

$V_{t}=V_{\text {cell }}-V_{\mathrm{S}_{\mathrm{O}}}+V_{\mathrm{RW}_{t}}-V_{\mathrm{H}_{t}}$

where $V_{\text {cell }}$ is the volume of cell $\left(460 \mathrm{~cm}^{3}\right), V_{\mathrm{S}_{0}}$ is the initial volume of the solution injected into the cell $\left(100 \mathrm{~cm}^{3}\right), V_{\mathrm{RW}}$, is the volume of reacted water, and $V_{\mathrm{H}_{t}}$ is the volume of produced hydrate.

The amounts of methane gas consumption in the process of hydrate formation are obtained from Eq. (1). In Figs. 8, 9, 10, and 11, the amounts of methane gas consumed during the formation of hydrate in the presence of carbon nanostructures and pure water are observed at $t=250 \mathrm{~min}$. According to the figures, the methane gas molecules are trapped at a high rate in the first stage (the first $60 \mathrm{~min}$ of hydration formation), which causes a high gas consumption rate; finally, hydrate is formed

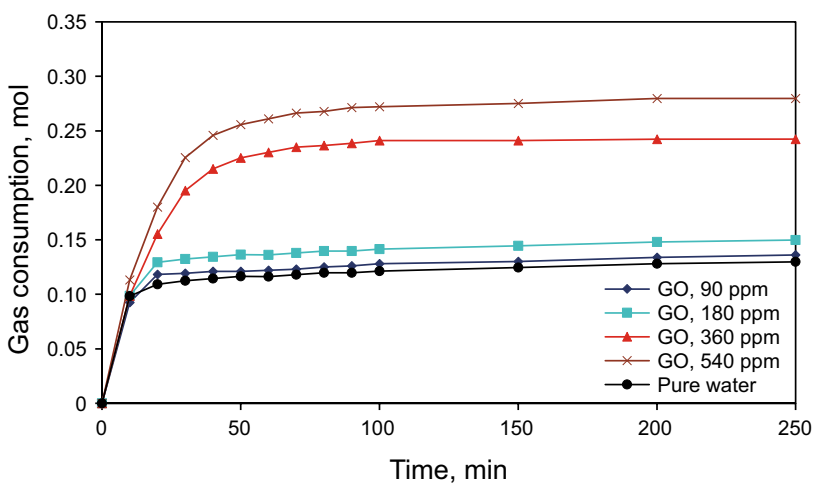

Fig. 8 The amount of methane gas consumed at $1{ }^{\circ} \mathrm{C}$ and $4.5 \mathrm{MPa}$ for different concentrations of graphene oxide compared to pure water

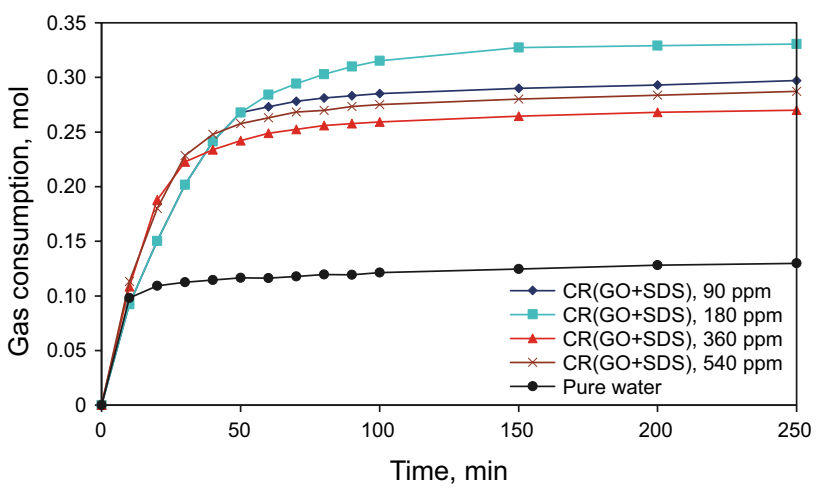

Fig. 9 The amount of methane gas consumed at a pressure of 4.5 $\mathrm{MPa}$ and a temperature of $1{ }^{\circ} \mathrm{C}$ for different concentrations of chemically reduced graphene oxide with $\mathrm{CR}(\mathrm{GO}+\mathrm{SDS})$ compared to pure water

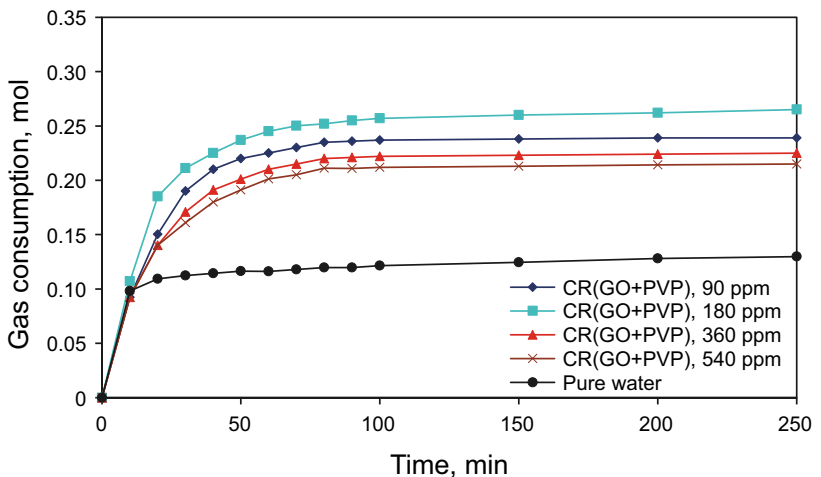

Fig. 10 The amount of methane gas consumed at a pressure of 4.5 $\mathrm{MPa}$ and a temperature of $1{ }^{\circ} \mathrm{C}$ with different concentrations of chemically reduced graphene oxide $\mathrm{CR}(\mathrm{GO}+\mathrm{PVP})$ and with pure water

at this stage. In the second stage (from $t=60 \mathrm{~min}$ to the end of hydrate formation), the amount of gas consumed is reduced and the system reaches a steady state. Figure 8 


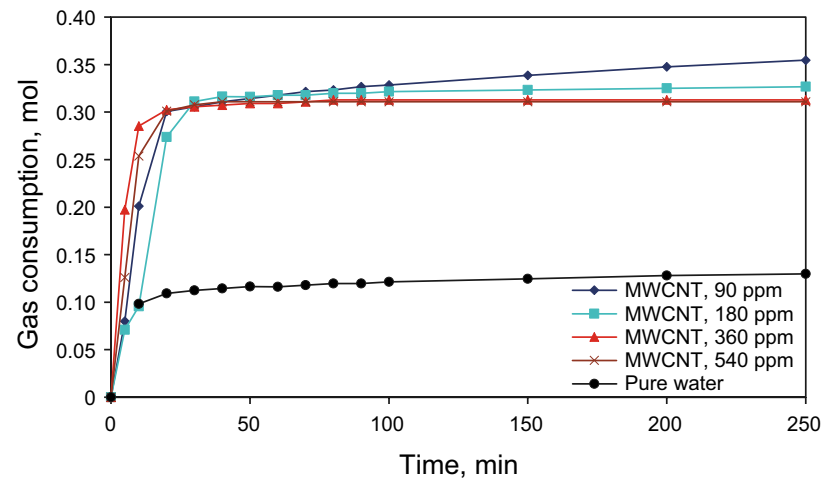

Fig. 11 Amount of methane gas consumed at a pressure of 4.5 MPa and a temperature of $1{ }^{\circ} \mathrm{C}$ with different concentrations of multiwalled carbon nanotubes (MWCNT) and with pure water

demonstrates the amount of methane gas consumed during the formation of hydrate in the presence of graphene oxide at the concentrations of $90,180,360,540 \mathrm{ppm}$ and pure water. As can be inferred from Fig. 8 , at the concentrations of 90 and $180 \mathrm{ppm}$, the methane gas consumed did not increase much compared to pure water, while the highest amount of gas consumed was observed at a concentration of $540 \mathrm{ppm}$, which at the end of hydrate formation was $0.2797 \mathrm{~mol}$ at the given concentration. This indicated a $215 \%$ increase, compared to the case of pure water with a value of $0.1297 \mathrm{~mol}$; these results are in agreement with what Rezaei et al. (2016) reported. The positive effect of graphene oxide is probably because graphene nanosheets provide a high specific surface area-to-volume ratio.

The methane gas consumption amounts in the process of hydrate formation in the presence of chemically reduced graphene oxide with SDS (CR(GO + SDS $)$ ) and chemically reduced graphene oxide with PVP $(\mathrm{CR}(\mathrm{GO}+\mathrm{PVP}))$ are displayed in Figs. 9 and 10 at the concentrations of 90,180, 360 , and $540 \mathrm{ppm}$.

As shown in Fig. 9, the maximum amount of methane gas consumed was at a concentration of $180 \mathrm{ppm}$, which at the end of the reaction reached $0.3305 \mathrm{~mol}$, and increased $254 \%$ compared to pure water with the value of 0.1297 . Also, in Fig. 10, the highest amount of methane gas consumed is $180 \mathrm{ppm}$, which at the end of the reaction reached $0.265 \mathrm{~mol}$. The latter is $204 \%$ higher than that of pure water, with a value of 0.1297 .

Reduced graphene oxide nanostructures, due to their high electrical conductivity, increase the heat transfer (Balandin et al. 2008). It is likely that SDS and PVP decrease the surface tension of water molecules and reduced graphene oxide nanostructures increase the available surface area by increasing the mass transfer of aqueous solutions and, consequently, provide suitable locations for nucleation.
Figure 11 shows the amount of methane gas consumed during the hydrate formation in the presence of multi-walled carbon nanotubes (MWCNT) at the concentrations of 90, 180,360 , and $540 \mathrm{ppm}$. The highest amount of methane gas consumption appeared at $90 \mathrm{ppm}$ concentration of multiwalled carbon nanotubes and reached $0.3547 \mathrm{~mol}$ at the end of hydrate formation, $173 \%$ higher than that in pure water case (with a methane gas consumption of $0.1297 \mathrm{~mol}$ ).

Park et al. (2010) reported that the amount of methane gas consumption in the presence of carbon nanotubes at $40 \mathrm{ppm}$ had a $300 \%$ increase compared to that in pure water, in accordance with the results of this study.

Given the hydrophobic properties of carbon nanotubes, it seems they are a good place for nucleation.

Suitable properties of thermal conductivity of carbon nanotubes (Ding et al. 2006) increase the heat transfer of the liquid phase as the former is added to it and consequently leads to an increase in the reaction rate of the hydrate formation. This eventually increases the rate of gas consumption. To obtain the formation rate of hydrate, the model reported by Englezos et al. (1987) was used:

$r=\frac{\mathrm{d} n_{\mathrm{H}}}{\mathrm{d} t}=-\frac{\mathrm{d} n_{\mathrm{G}}}{\mathrm{d} t}=K_{\text {app }}\left(f_{\mathrm{g}}-f_{\mathrm{eq}}\right)$

where $r$ is the instantaneous velocity of hydrate formation, $n_{\mathrm{H}}$ is the number of produced hydrate moles, and $n_{G}$ is the number of consumed gas molecules. $K_{\text {app }}$ represents the initial apparent rate constant of hydrate formation, $f_{\mathrm{g}}$ is the fugacity of gas molecules in the gas phase, and $f_{\text {eq }}$ shows the fugacity of gas molecules under equilibrium conditions ( $T$ and $P_{\text {eq }}$ ). $f_{g}$ is calculated using the Peng-Robinson equation of state (Peng and Robinson 1976), and the equilibrium pressure of the hydrate formation, $P_{\text {eq }}$, can be calculated from van der Waals-Platteeuw model (van der Waals and Platteeuw 1958).

Figures 12, 13, 14 and 15 show the rate of gas uptake during hydrate formation in the presence of carbon nanostructures compared to pure water. According to these figures, the highest hydrate formation rate occurs in the first $20 \mathrm{~min}$ of the reaction, when numerous hydrates nucleate. Subsequently, due to the increase in temperature, the hydrate formation rate is reduced. As can be seen, by increasing the carbon nanostructures, the hydrate formation rate increases.

The supersaturation (driving force) of gas hydrate formation process is the difference between the pressure of the cell and the equilibrium pressure at the test temperature. During the hydrate formation process, the amount of methane in the gas phase decreases. By decreasing the amount of methane in the gas phase, the pressure of the cell drops and subsequently, the supersaturation declines and growth rate decreases. As can be seen in Figs. 12, 13, 14 and 15, the additives used remarkably increase the hydrate growth rate. Utilization of carbon nanostructures causes heterogeneous nucleation. Because, there are more nuclei 


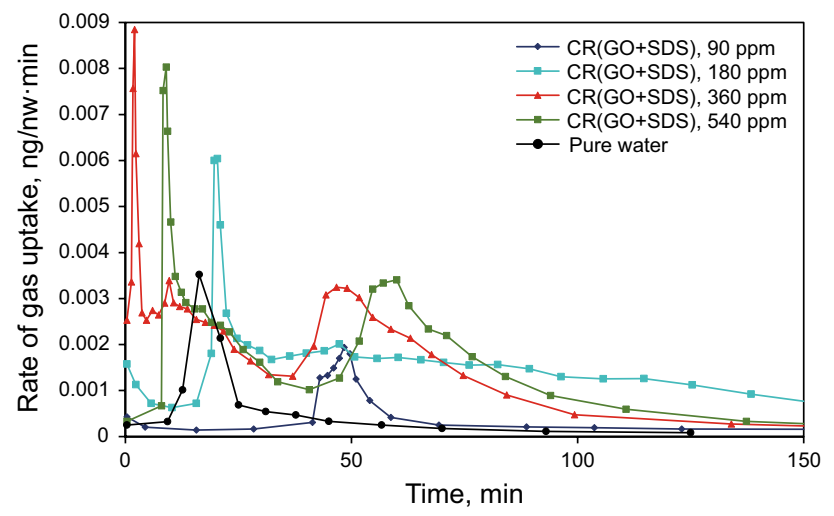

Fig. 12 Rate of gas uptake during hydrate formation at $1{ }^{\circ} \mathrm{C}$ and 4.5 $\mathrm{MPa}$ for different concentrations of chemically reduced graphene oxide $\mathrm{CR}(\mathrm{GO}+\mathrm{SDS})$ compared to pure water

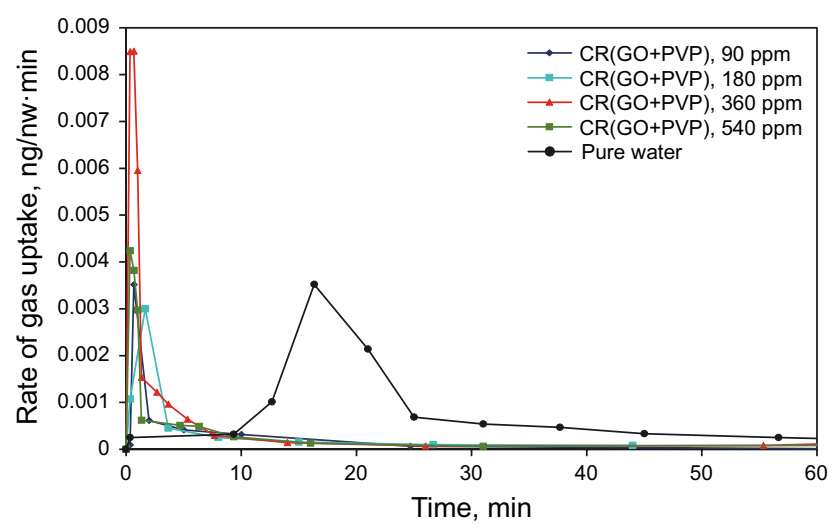

Fig. 13 Rate of gas uptake during hydrate formation at $1{ }^{\circ} \mathrm{C}$ and 4.5 $\mathrm{MPa}$ for different concentrations of chemically reduced graphene oxide $\mathrm{CR}(\mathrm{GO}+\mathrm{PVP})$ compared to pure water

in the solutions containing carbon nanostructures, compared to pure water, the amount of gas uptake for these solutions is more than that of pure water and consequently, the hydrate growth rate for these solutions is more than that of pure water.

\subsection{Storage capacity and water to hydrate conversion percentage}

The storage capacity is expressed by Eq. (4) which is equal to the volume of gas trapped in the hydrate structure to the volume of the empty hydrate network, under standard temperature and pressure conditions.

$S C=\frac{V_{\mathrm{STP}}}{V_{\mathrm{H}}}=\frac{\Delta n R T_{\mathrm{STP}} / P_{\mathrm{STP}}}{V_{\mathrm{H}}}$

where " $V_{\mathrm{STP}}$ " is the amount of the gas being trapped under standard temperature and pressure conditions and " $V_{\mathrm{H}}$ " is the volume of gas hydrate produced from reacted water, derived

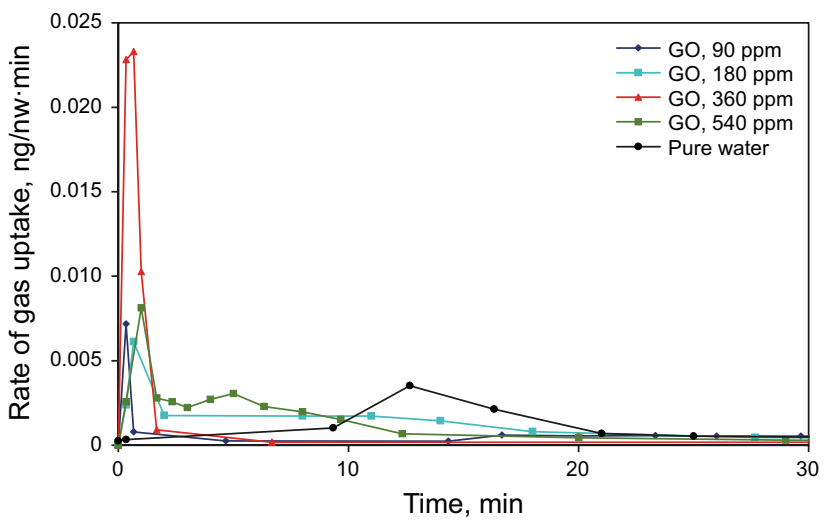

Fig. 14 Rate of gas uptake during hydrate formation at $1{ }^{\circ} \mathrm{C}$ and 4.5 $\mathrm{MPa}$ for different concentrations of graphene oxide compared to pure water

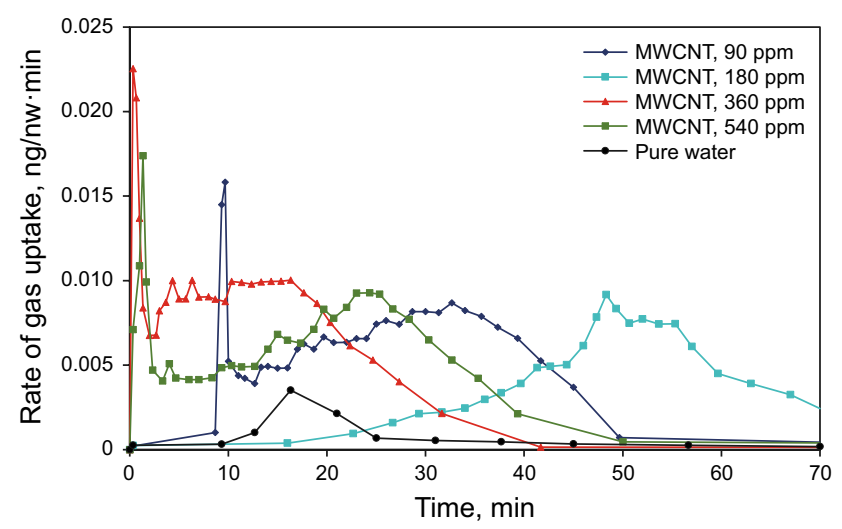

Fig. 15 Rate of gas uptake during hydrate formation at $1{ }^{\circ} \mathrm{C}$ and 4.5 MPa for different concentrations of multi-walled carbon nanotube (MWCNT) compared to pure water

from Eq. (5). " $\Delta n$ ", $R, T$, and $P$ are the moles of gas trapped in hydrate, the global constant for gases, the temperature, and the pressure, respectively.

$V_{\mathrm{H}}=M \times \Delta n \times v_{\mathrm{w}}^{\mathrm{MT}}$

To calculate the empty volume of clathrate hydrate $\left(v_{\mathrm{w}}^{\mathrm{MT}}\right)$ in structure I, which has a structure similar to methane hydrate, Eq. (6) is used (Klauda and Sandler 2000):

$$
\begin{aligned}
v_{\mathrm{w}}^{\mathrm{MT}}(I)= & \left(11.835+2.217 \times 10^{-5} T+2.242 \times 10^{-6} T^{2}\right)^{3} \\
& \times \frac{10^{-30} N_{\mathrm{A}}}{46}-8.006 \times 10^{-9} P+5.448 \times 10^{-12} P^{2}
\end{aligned}
$$

where $v_{\mathrm{w}}^{\mathrm{MT}}$ is the molar volume of the empty hydrate network per cubic meters per mole, and $N_{\mathrm{A}}, T$, and $P$ are Avogadro number, the equilibrium temperature in ${ }^{\circ} \mathrm{C}$, and the equilibrium pressure in $\mathrm{MPa}$, respectively.

Figure 16 illustrates the storage capacity of methane hydrate in the presence of carbon nanostructures and pure water. Based 
Fig. 16 Storage capacity of formed methane hydrate in the presence of carbon nanostructures and pure water at a pressure of $4.5 \mathrm{MPa}$ and a temperature of $1{ }^{\circ} \mathrm{C}$

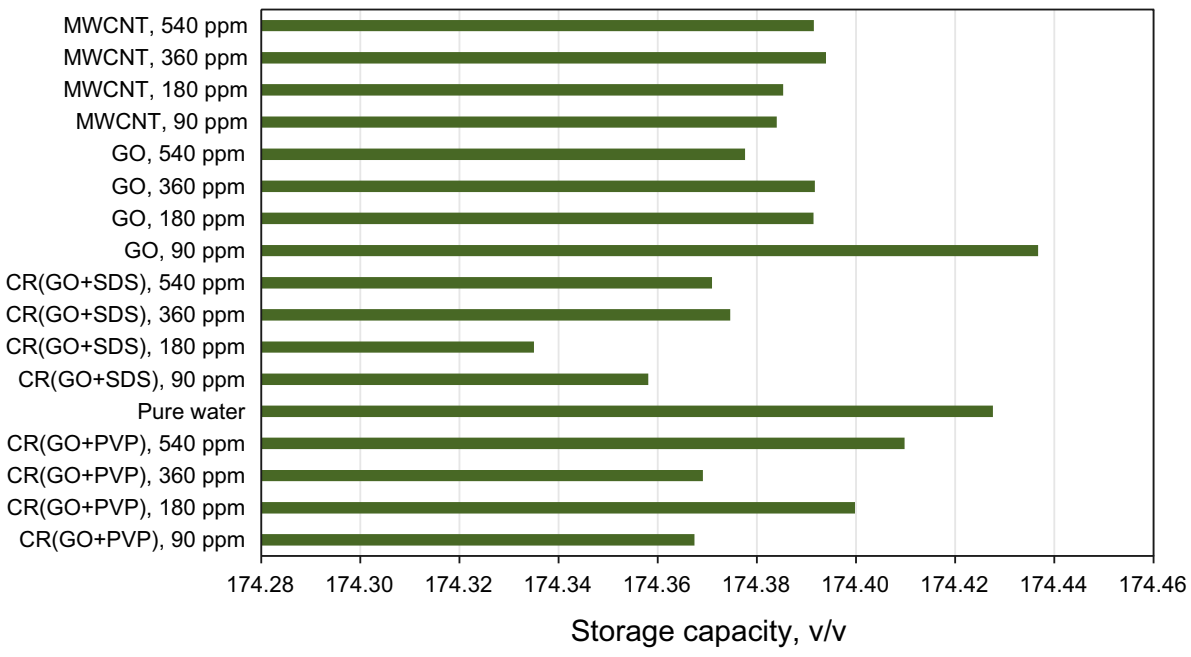

on Fig. 16, carbon nanotubes do not have a notable effect on storage capacity, which is because the storage capacity is not a kinetic parameter.

The percentage of water to hydrate conversion, which is calculated at the end of hydrate formation reaction, is the number of water moles converted into hydrate per moles of water. The following equation can be used to calculate the percentage of water converted to hydrate (Dreyer et al. 2010; Fernández-Merino et al. 2010; Rezaei et al. 2016; Mohammadi et al. 2014; Najibi et al. 2015; Aliabadi et al. 2015; Govindaraj et al. 2015):

Conversion $=\frac{M \times \Delta n}{n_{\mathrm{w}_{0}}} \times 100$

In the above equation, $M$ represents the hydrate number, being 5.75 for carbon dioxide, and $n_{\mathrm{w}_{\mathrm{o}}}$ is water's initial mole number.

In Fig. 17, the water to hydrate conversion percentage at the end of hydrate formation is shown for all carbon nanostructures compared to pure water. As can be seen, the results of the water to hydrate conversion at the end of hydrate formation are better than the pure water in all concentrations of carbon nanostructures. The greatest percentage of water to hydrate conversion was obtained in the concentration of $90 \mathrm{ppm}$ for multi-walled carbon nanotubes. This is equal to $71.6 \mathrm{~mol} \%$ indicating an increase of $253 \%$ compared to the case of pure water, which stands at the value of $28.3 \%$. The reason for these increases compared to pure water is the increase in the reaction kinetic velocity and the amount of gas consumed by carbon nanotubes. In addition, as stated earlier, the hydrate formation is accompanied by a pressure drop. The closer the pressure (reaction pressure) at the end of hydrate formation is to the equilibrium pressure, the more the percentage of water to hydrate conversion becomes.

Carbon nanostructures (GO and MWCNTs) are expensive additives, but the experimental investigation of the effect of tested carbon nanostructures shows that utilization of low
Fig. 17 Effect of nanostructure on water to hydrate conversion of methane hydrate formation process under the conditions of 4.5 $\mathrm{MPa}$ and $1{ }^{\circ} \mathrm{C}$

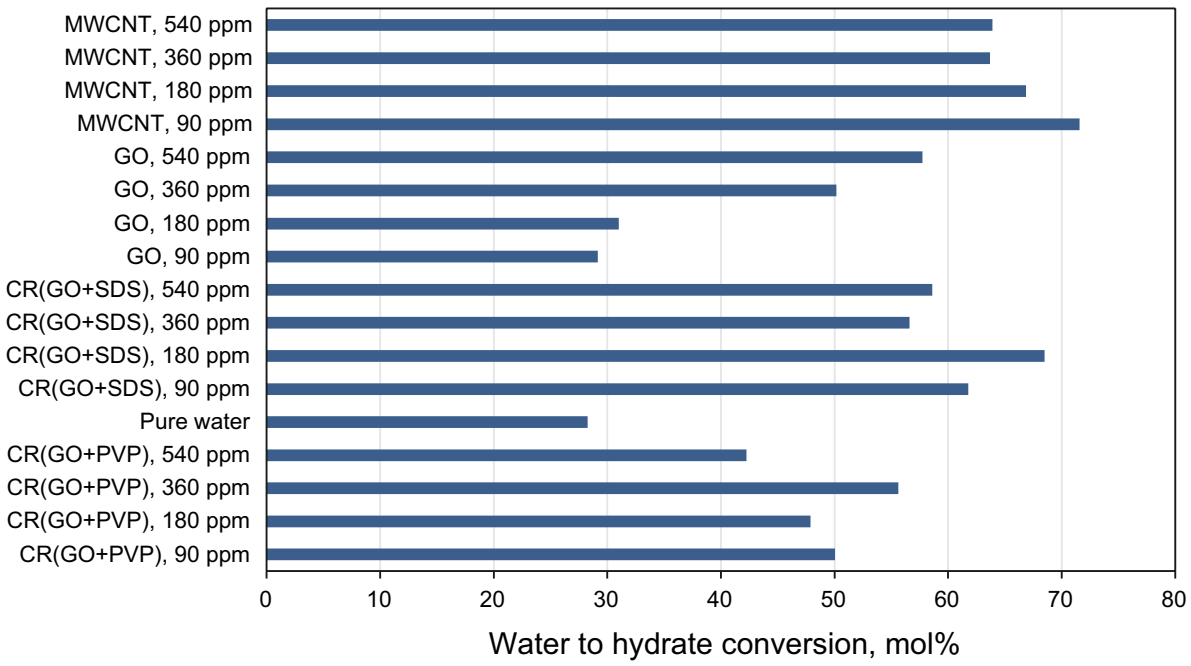


concentrations of these additives promotes the kinetics of methane hydrate formation, significantly. The use of low concentrations of carbon nanostructures can reduce the costs of hydrate formation process.

\section{Conclusion}

In this research, the effect of carbon nanostructures on the rate and amount of gas consumption, water to hydrate conversion, and the storage capacity in the process of the hydrate formation was investigated. The results of the experiments show that the addition of carbon nanostructures reduces the induction time; the lowest induction time in the presence of chemically reduced graphene oxide with SDS and graphene oxide occurrs at a concentration of 360 and $180 \mathrm{ppm}$, respectively. The amount of methane gas is consumed during the hydrate formation increases with the addition of carbon nanostructures, and the highest amount of methane gas isconsumed at a concentration of $90 \mathrm{ppm}$ of multi-walled carbon nanotube. In fact, carbon nanotubes increase the amount of methane gas consumption. However, the storage capacity is not affected by carbon nanostructures at the end of hydrate formation. Furthermore, the percentage of water to hydrate conversion in the presence of carbon nanotubes increases significantly, and the highest level of increase is in the presence of multi-walled carbon nanotubes at a concentration of $90 \mathrm{ppm}$.

Open Access This article is distributed under the terms of the Creative Commons Attribution 4.0 International License (http://creativeco mmons.org/licenses/by/4.0/), which permits unrestricted use, distribution, and reproduction in any medium, provided you give appropriate credit to the original author(s) and the source, provide a link to the Creative Commons license, and indicate if changes were made.

\section{References}

Abedi-Farizhendi S, Rahmati-Abkenar M, Manteghian M, Yekshaveh JS, Zahmatkeshan V. Kinetic study of propane hydrate in the presence of carbon nanostructures and SDS. J Pet Sci Eng. 2018;172:636-42. https://doi.org/10.1016/j.petrol.2018.04.075.

Adisasmito S, Frank RJ III, Sloan ED Jr. Hydrates of carbon dioxide and methane mixtures. J Chem Eng Data. 1991;36(1):68-71. https ://doi.org/10.1021/je00001a020.

Aliabadi M, Rasoolzadeh A, Esmaeilzadeh F, Alamdari A. Experimental study of using $\mathrm{CuO}$ nanoparticles as a methane hydrate promoter. J Nat Gas Sci Eng. 2015;27:1518-22. https://doi. org/10.1016/j.jngse.2015.10.017.

Arjang S, Manteghian M, Mohammadi A. Effect of synthesized silver nanoparticles in promoting methane hydrate formation at $4.7 \mathrm{MPa}$ and 5.7 MPa. Chem Eng Res Des. 2013;91(6):1050-4. https://doi. org/10.1016/j.cherd.2012.12.001.
Balandin AA, Ghosh S, Bao W, Calizo I, Teweldebrhan D, Miao F, et al. Superior thermal conductivity of single-layer graphene. Nano Lett. 2008;8(3):902-7. https://doi.org/10.1021/n10731872.

Basha MAF. Magnetic and optical studies on polyvinylpyrrolidone thin films doped with rare earth metal salts. Polym J. 2010;42(9):728. https://doi.org/10.1038/pj.2010.60.

Chari VD, Sharma DV, Prasad PS, Murthy SR. Methane hydrates formation and dissociation in nano silica suspension. J Nat Gas Sci Eng. 2013;11:7-11. https://doi.org/10.1016/j.jngse.2012.11.004.

Chatti I, Delahaye A, Fournaison L, Petitet J-P. Benefits and drawbacks of clathrate hydrates: a review of their areas of interest. Energy Convers Manag. 2005;46(9):1333-43. https://doi.org/10.1016/j. enconman.2004.06.032.

Christiansen R, Sloan Jr E. A compact model for hydrate formation: Gas Processors Association, Tulsa, OK (United States), 1995.

Chua CK, Pumera M. Reduction of graphene oxide with substituted borohydrides. J Mater Chem A. 2013;1(5):1892-8. https://doi. org/10.1039/C2TA00665K.

Ding Y, Alias H, Wen D, Williams RA. Heat transfer of aqueous suspensions of carbon nanotubes (CNT nanofluids). Int J Heat Mass Transf. 2006;49(1-2):240-50. https://doi.org/10.1016/j.ijheatmass transfer.2005.07.009.

Dreyer DR, Park S, Bielawski CW, Ruoff RS. The chemistry of graphene oxide. Chem Soc Rev. 2010;39(1):228-40. https://doi. org/10.1039/B917103G.

Englezos P, Kalogerakis N, Dholabhai PD, Bishnoi PR. Kinetics of formation of methane and ethane gas hydrates. Chem Eng Sci. 1987;42(11):2647-58. https://doi.org/10.1016/00092509(87)87015-X.

Eslamimanesh A, Mohammadi AH, Richon D, Naidoo P, Ramjugernath $\mathrm{D}$. Application of gas hydrate formation in separation processes: a review of experimental studies. J Chem Thermodyn. 2012;46:62-71. https://doi.org/10.1016/j.jct.2011.10.006.

Fernández-Merino MJ, Guardia L, Paredes J, Villar-Rodil S, SolísFernández P, Martínez-Alonso A, et al. Vitamin C is an ideal substitute for hydrazine in the reduction of graphene oxide suspensions. J Phys Chem C. 2010;114(14):6426-32. https://doi. org/10.1021/jp100603h.

Ganji H, Aalaie J, Boroojerdi S, Rod AR. Effect of polymer nanocomposites on methane hydrate stability and storage capacity. J Pet Sci Eng. 2013;112:32-5. https://doi.org/10.1016/j.petro 1.2013.11.026.

Govindaraj V, Mech D, Pandey G, Nagarajan R, Sangwai JS. Kinetics of methane hydrate formation in the presence of activated carbon and nano-silica suspensions in pure water. J Nat Gas Sci Eng. 2015;26:810-8. https://doi.org/10.1016/j.jngse.2015.07.011.

Ji C, Ahmadi G, Smith DH. Natural gas production from hydrate decomposition by depressurization. Chem Eng Sci. 2001;56(20):5801-14. https://doi.org/10.1016/S0009 $-2509(01) 00265-2$.

Klauda JB, Sandler SI. A fugacity model for gas hydrate phase equilibria. Ind Eng Chem Res. 2000;39(9):3377-86. https://doi. org/10.1021/ie000322b.

Mohammadi A. Effect of SDS, silver nanoparticles, and SDS + silver nanoparticles on methane hydrate semicompletion time. Pet Sci Technol. 2017;35(15):1542-8. https://doi.org/10.1080/10916 466.2017.1316736.

Mohammadi A, Manteghian M, Haghtalab A, Mohammadi AH, Rahmati-Abkenar M. Kinetic study of carbon dioxide hydrate formation in presence of silver nanoparticles and SDS. Chem Eng J. 2014;237:387-95. https://doi.org/10.1016/j.cej.2013.09.026.

Mohammadi A, Manteghian M, Jahangiri A. Measurement of the amount and rate of methane dissolution in pure water and aqueous solution of SDS + multi-wall carbon nanotubes $+\beta$-cyclodextrin. Pet Sci Technol. 2017a;35(15):1549-55. https://doi. org/10.1080/10916466.2017.1316737. 
Mohammadi A, Manteghian M, Mirzaei M. Effect of $\beta$-cyclodextrin on dissolution of methane in water. Chem Eng Res Des. 2011;89(4):421-7. https://doi.org/10.1016/j.cherd.2010.07.011.

Mohammadi A, Manteghian M, Mohammadi AH, Jahangiri A. Induction time, storage capacity, and rate of methane hydrate formation in the presence of SDS and silver nanoparticles. Chem Eng Commun. 2017b;204(12):1420-7. https://doi.org/10.1080/00986 445.2017.1366903.

Mohammadi A, Pakzad M, Mohammadi A, Jahangiri A. Kinetics of $\left(\mathrm{TBAF}+\mathrm{CO}_{2}\right)$ semi-clathrate hydrate formation in the presence and absence of SDS. Pet Sci. 2018; 1-10. https://doi.org/10.1021/ je00001a020.

Najibi H, Mirzaee Shayegan M, Heidary H. Experimental investigation of methane hydrate formation in the presence of copper oxide nanoparticles and SDS. J Nat Gas Sci Eng. 2015;23:315-23. https ://doi.org/10.1016/j.jngse.2015.02.009.

Ohgaki K, Takano K, Sangawa H, Matsubara T, Nakano S. Methane exploitation by carbon dioxide from gas hydrates Phase equilibria for $\mathrm{CO}_{2}-\mathrm{CH}_{4}$ mixed hydrate system. J Chem Eng Jpn. 1996;29(3):478-83. https://doi.org/10.1252/jcej.29.478.

Pahlavanzadeh H, Rezaei S, Khanlarkhani M, Manteghian M, Mohammadi AH. Kinetic study of methane hydrate formation in the presence of copper nanoparticles and CTAB. J Nat Gas Sci Eng. 2016;34:803-10. https://doi.org/10.1016/j.jngse.2016.07.001.

Park S-S, An E-J, Lee S-B, Chun W-G, Kim N-J. Characteristics of methane hydrate formation in carbon nanofluids. J Ind Eng Chem. 2012;18(1):443-8. https://doi.org/10.1016/j.jiec.2011.11.045.

Park S-S, Lee S-B, Kim N-J. Effect of multi-walled carbon nanotubes on methane hydrate formation. J Ind Eng Chem. 2010;16(4):5515. https://doi.org/10.1016/j.jiec.2010.03.023.

Pasieka J, Jorge L, Coulombe S, Servio P. Effects of as-produced and amine-functionalized multi-wall carbon nanotubes on carbon dioxide hydrate formation. Energy Fuels. 2015;29(8):5259-66. https://doi.org/10.1021/acs.energyfuels.5b01036.

Peng D-Y, Robinson DB. A new two-constant equation of state. Ind Eng Chem Fundam. 1976;15(1):59-64. https://doi.org/10.1021/ i160057a011.
Rahmati-Abkenar M, Manteghian M, Pahlavanzadeh H. Experimental and theoretical investigation of methane hydrate induction time in the presence of triangular silver nanoparticles. Chem Eng Res Des. 2017;120:325-32. https://doi.org/10.1016/j.cherd .2017.02.023.

Rezaei E, Manteghian M, Tamaddondar M. Kinetic study of ethylene hydrate formation in presence of graphene oxide and sodium dodecyl sulfate. J Pet Sci Eng. 2016;147:857-63. https://doi. org/10.1016/j.petrol.2016.10.008.

Said S, Govindaraj V, Herri J-M, Ouabbas Y, Khodja M, Belloum $\mathrm{M}$, et al. A study on the influence of nanofluids on gas hydrate formation kinetics and their potential: application to the $\mathrm{CO}_{2}$ capture process. J Nat Gas Sci Eng. 2016;32:95-108. https://doi. org/10.1016/j.jngse.2016.04.003.

Sloan JED, Koh KA. Clathrate Hydrates of Natural Gases. 3rd ed. Taylor \& Francis Group: CRC Press; 2008.

Smith JM, Van Ness HC, Abbott MM. Introduction to chemical engineering thermodynamics. McGraw-Hill; 2005.

Tran DN, Kabiri S, Losic D. A green approach for the reduction of graphene oxide nanosheets using non-aromatic amino acids. Carbon. 2014;76:193-202. https://doi.org/10.1016/j.carbon.2014.04.067.

van der Waals JH, Platteeuw JC. Clathrate solutions. In: Prigogine, editor. Advances in Chemical Physics. 1958.

Waltman R, Pacansky J, Bates C Jr. X-ray photoelectron spectroscopic studies on organic photoconductors: evaluation of atomic charges on chlorodiane blue and p-(diethylamino) benzaldehyde diphenylhydrazone. Chem Mater. 1993;5(12):1799-804. https://doi. org/10.1021/cm00036a018.

Zhao L, Gao L. Coating multi-walled carbon nanotubes with zinc sulfide. J Mater Chem. 2004;14(6):1001-4. https://doi. org/10.1039/B315450E.

Zhou S-D, Yu Y-S, Zhao M-M, Wang S-L, Zhang G-Z. Effect of graphite nanoparticles on promoting $\mathrm{CO}_{2}$ hydrate formation. Energy Fuels. 2014;28(7):4694-8. https://doi.org/10.1021/ef5000886. 